\title{
Análise de imagens na avaliação de danos mecânicos em sementes de soja ${ }^{1}$
}

\author{
Taís Leite Ferreira Pinto ${ }^{2}$, Vitor Henrique Vaz Mondo², \\ Francisco Guilhien Gomes-Júnior ${ }^{2}$, Silvio Moure Cicero ${ }^{2}$
}

\begin{abstract}
Image analysis for evaluating

mechanical damages in soybean seeds

Mechanical damage is one of the most important factors in the soybean seeds quality decrease. This study aimed at evaluating the influence of impact pressure and seed moisture content, as well as the applicability of image analysis, on mechanical damages in soybean seeds. Vencedora and Monsoy 8001 cultivars seeds, with moisture content of $13 \%$ and $18 \%$, were submitted to mechanical damages, with the aid of an impact simulator equipment (551.6 KPa and $965.3 \mathrm{KPa})$. Subsequently, the seeds were dried at $32^{\circ} \mathrm{C}$ up to $12 \%$ of moisture content. Immediately after the impacts and after five months of storage, the seeds were submitted to the tetrazolium and X-rays tests. The impact pressure and seed moisture content directly affected the mechanical damages severity, however, the impact location presented a higher influence than those factors. The image analysis method was very useful for evaluating mechanical damages in soybean seeds, enabling a detailed analysis of different factors effects.
\end{abstract}

KEY-WORDS: Glycine max (L.) Merrill.; physiological potential; seed quality; X-rays.

\section{INTRODUÇÃO}

No processo de produção de sementes, estas são submetidas a uma série de etapas, para a obtenção de lotes de alta qualidade. Dentre estas, a colheita, o transporte, a movimentação e o beneficiamento sujeitam as sementes a impactos potencialmente causadores de injúrias mecânicas. Assim, os impactos e os danos ocasionados em sementes são praticamente inevitáveis, dentro deste processo, pois podem ocorrer em várias etapas mecanizadas e ser agravados a cada dia, haja vista a demanda crescente por mecanização do setor agrícola, o que mantém o dano mecânico como um dos problemas mais sérios na área de tecnologia de sementes.

\section{RESUMO}

A injúria mecânica é um dos mais importantes fatores na redução da qualidade de sementes de soja. Neste contexto, este trabalho objetivou avaliar a influência da pressão de impacto e o teor de água em sementes, bem como a aplicabilidade da técnica de análise de imagens, na ocorrência de danos mecânicos em sementes de soja. Sementes das cultivares Vencedora e Monsoy 8001 , com teores de água de $13 \%$ e $18 \%$, foram submetidas a danos mecânicos, com a utilização de equipamento simulador de impactos (551,6 KPa e 965,3 KPa). Posteriormente, as sementes foram secas a $32^{\circ} \mathrm{C}$, até atingirem $12 \%$ de teor de água. Imediatamente após os impactos e após cinco meses de armazenamento, as sementes foram avaliadas pelos testes de tetrazólio e raios X. A pressão de impacto e o teor de água nas sementes exerceram efeitos diretos na severidade do dano mecânico, porém, o local do impacto exerceu maior influência do que aqueles fatores. A técnica de análise de imagens foi de grande utilidade na avaliação de danos mecânicos em sementes de soja, possibilitando a análise detalhada dos efeitos de diferentes fatores.

PALAVRAS-CHAVE: Glycine max (L.) Merrill.; potencial fisiológico; qualidade de sementes; raios X.

Segundo Carvalho \& Nakagawa (2000), mesmo com a perfeita regulagem das máquinas, podem ocorrer danos em intensidades variáveis, ou seja, a sua ocorrência é inevitável. Tais danos são provocados por impactos nas sementes, em virtude de vários fatores, como teor de água e tensão aplicada na queda das sementes, dureza e características genotípicas do material, dentre outros (Andrade et al. 1999). Além disto, no caso da soja, a própria espécie possui características que propiciam a alta incidência de danos mecânicos, uma vez que as partes vitais do eixo embrionário, como radícula, hipocótilo e plúmula, estão situadas sob tegumento pouco espesso, o qual, praticamente, não lhe oferece proteção (França Neto \& Henning 1984).

1. Trabalho recebido em jun./2012 e aceito para publicação em set./2012 (nº registro: PAT 18847).

2. Universidade de São Paulo (USP), Escola Superior de Agricultura "Luiz de Queiroz" (ESALQ), Departamento de Produção Vegetal, Piracicaba, SP, Brasil.E-mails: tais_leite@yahoo.com, vhvmondo@yahoo.com.br, francisco1@usp.br, smcicero@usp.br. 
O teor de água recomendado para a colheita mecanizada de sementes de soja é de $12-15,9 \%$ (Carvalho \& Novembre 2012), pois minimiza perdas e a ocorrência de danos mecânicos. Sementes colhidas com teor de água superior a $16 \%$ estão sujeitas a maior incidência de danos mecânicos latentes e, quando colhidas com teor abaixo de $12 \%$, estão mais susceptíveis ao dano mecânico imediato (Embrapa 2005).

Resultados de pesquisas evidenciam que sementes de soja colhidas com teor de água de 13\% proporcionaram menores índices de danos mecânicos, quebra de sementes e impurezas, indicando que, neste teor, a semente de soja apresenta melhor padrão de qualidade (Costa et al. 2002). A operação de colheita antecipada, sendo realizada com teores de água na semente em torno de $18 \%$, pode ser adotada, caso o produtor tenha conhecimento das regulagens do sistema de trilha, visando à não ocorrência de elevados índices de danos mecânicos latentes, desde que aliada à disponibilidade de estrutura adequada de secadores (França Neto et al. 2007).

Trabalhos envolvendo danos mecânicos em sementes vêm sendo realizados com a utilização de dispositivos para provocar danos de forma controlada (Andrade et al. 1998, Andrade et al. 1999, Obando-Flor et al. 2004, Mondo et al. 2009, Carvalho et al. 2011), sendo considerados ótima técnica para este tipo de estudo (Carvalho et al. 2011). Outra técnica importante, atualmente utilizada para o estudo de danos mecânicos em sementes, é a análise de imagens (Cicero et al. 1998, Cicero \& Banzatto Júnior 2003, Obando-Flor et al. 2004, Mondo et al. 2009), que é considerada rápida, precisa e não destrutiva, permitindo o estudo externo e interno das sementes e o estabelecimento de relações de causa e efeito.

Nesse contexto, este trabalho objetivou avaliar a influência da pressão de impacto e o teor de água das sementes na ocorrência de danos mecânicos em sementes de soja, bem como a aplicabilidade da técnica da análise de imagens, neste tipo de estudo.

\section{MATERIAL E MÉTODOS}

A pesquisa foi realizada nos Laboratórios de Análise de Sementes e de Análise de Imagens do Departamento de Produção Vegetal da Universidade de São Paulo, Escola Superior de Agricultura "Luiz de Queiroz", em Piracicaba (SP), durante o ano de 2008.
Foram utilizadas sementes das cultivares Vencedora e Monsoy 8001, produzidas na safra $2006 / 2007$, as quais apresentavam, inicialmente, teor de água em torno de 7\%. Para tanto, estipulou-se o tratamento controle, utilizando-se sementes com $12 \%$ de teor de água e não submetidas a danos mecânicos, e duas amostras de sementes, uma com teor de água de $13 \%$ e outra com $18 \%$, ambas submetidas a duas pressões de impacto $(\mathrm{P} 1=551,6 \mathrm{KPa}$ e $\mathrm{P} 2=965,3 \mathrm{KPa})$, totalizando, com o controle, cinco tratamentos para cada cultivar. Para o ajuste do teor de água a $12 \%, 13 \%$ e $18 \%$, foi utilizada a metodologia da atmosfera controlada (Rosseto et al. 1995). Adotou-se o delineamento inteiramente casualizado, com quatro repetições.

As amostras de sementes com os teores de água de $13 \%$ e $18 \%$ foram submetidas a danos mecânicos, com a utilização do equipamento simulador de impactos "BC Impact Simulator - Model 2000", que possibilita arremessar as sementes, por meio de jato de ar comprimido com pressão conhecida, contra uma placa de aço inoxidável, posicionada a $14,0 \mathrm{~cm}$ da entrada do jato de ar. As sementes foram arremessadas três vezes consecutivas, em cada tratamento, e, em seguida, foram secas à temperatura de $32^{\circ} \mathrm{C}$, até o teor de água de $12 \%$, para armazenamento (Henning \& França Neto 1993). No tratamento controle, as sementes foram hidratadas até $12 \%$ de teor de água. Para todas as avaliações de teor de água em sementes, utilizou-se o método da estufa (Brasil 2009).

Imediatamente após os impactos e após cinco meses de armazenamento (temperatura de $20^{\circ} \mathrm{C}$ e umidade relativa do ar de $45 \%$ ), as sementes foram avaliadas, quanto à ocorrência e severidade de danos mecânicos, por meio do teste de tetrazólio e da análise de imagens.

Para o teste de tetrazólio, foram utilizadas quatro repetições de 50 sementes de cada tratamento. As sementes foram pré-condicionadas em papel toalha convenientemente umedecido, durante 16 horas, em germinador a $25^{\circ} \mathrm{C}$. Decorrido este período, foram colocadas em copos plásticos $(50 \mathrm{~mL})$, sendo totalmente submersas na solução de tetrazólio a $0,075 \%$, e levadas a germinadores regulados a $40^{\circ} \mathrm{C}$, em ausência de luz, por período de 180 minutos. Em seguida, as sementes foram lavadas em água corrente e avaliadas individualmente, computando-se, como número de sementes potencialmente germináveis, aquelas incluídas nas classes 1 a 5 e, como potencialmente vigorosas, aquelas incluídas nas classes 1 a 3 . 
Na identificação dos danos mecânicos nas sementes, foram computados os danos totais (classes 1 a 6), danos que não interferiram no vigor das sementes (classes 1 a 3 ) e danos que inviabilizaram as sementes (classe 6), conforme proposto por França Neto (1999).

Para a análise de imagens, 50 sementes de cada tratamento foram dispostas em placas acrílicas com alvéolos individualizados, colocando-se, por baixo, fita adesiva transparente, para fixação das sementes na mesma posição.

As sementes foram numeradas de acordo com a posição ocupada na placa, de maneira que pudessem ser identificadas nas determinações posteriores, sendo a placa colocada diretamente sobre um filme radiográfico (Kodak MIN-R 2000, $18 \mathrm{~cm}$ x $24 \mathrm{~cm}$ ), à distância de $35,0 \mathrm{~cm}$ da fonte de radiação.

As imagens foram obtidas com intensidade de 25 KV e 40 segundos de exposição (Pinto et al. 2009), utilizando-se equipamento FAXITRON X-Ray, modelo MX-20, e a revelação efetuada em processadora Hope X-Ray, modelo 319 Micromax. Posteriormente, as imagens dos filmes de raios $\mathrm{X}$ foram digitalizadas em scanner Umax, modelo Powerlook 1100, para subsequente ampliação e visualização em computador.

Em sequência, as sementes foram submetidas ao teste de germinação, que foi conduzido com as sementes de cada tratamento, previamente numeradas e identificadas, distribuídas em grupos de 10, em duas fileiras de cinco sementes espaçadas sobre duas folhas de papel-toalha "Germitest", no terço superior do substrato, para permitir o desenvolvimento das plântulas de maneira individualizada, e enroladas e cobertas com mais uma folha de papel-toalha. As folhas de papel foram umedecidas com quantidade de água equivalente a 2,5 vezes a massa das mesmas e os rolos acondicionados em germinador e mantidos à temperatura de $25^{\circ} \mathrm{C}$ (Brasil 2009).

Decorridos cinco dias após a instalação do teste, as plântulas normais, anormais e as sementes mortas foram retiradas do substrato e fotografadas com câmera fotográfica digital Nikon, modelo D1, acoplada ao computador. Os danos mecânicos observados na análise radiográfica das sementes foram classificados como severo (injúria mecânica no eixo embrionário e/ou na região central dos cotilédones) e não severo (injúria mecânica na periferia dos cotilédones).

Os dados foram analisados separadamente para cada cultivar e época de armazenamento, sendo submetidos à análise de variância (teste F), e, quando encontradas diferenças, a comparação de médias foi realizada pelo teste Tukey, a 5\%.

\section{RESULTADOS E DISCUSSÃO}

Baseando-se nos resultados de percentagem de danos mecânicos obtidos por meio do teste de tetrazólio, para a cultivar Vencedora (Figura 1), observou-se que, para o número total de danos (Figura 1A), com teor de água de $13 \%$, apenas a maior pressão resultou em danos significativos. Porém, para o teor de água de $18 \%$, considerado elevado, menores pressões resultaram em efeitos negativos às sementes.

No entanto, observando-se os resultados dos testes após o armazenamento, verificou-se que os danos ficaram mais evidentes, sendo crescente a percentagem de danos mecânicos nas sementes, de acordo com o aumento da pressão de impacto. Isto evidencia que danos mecânicos latentes estavam vinculados às menores pressões e não puderam ser observados nas avaliações imediatamente após a aplicação dos impactos.

Resultados semelhantes para a análise pré-armazenamento foram encontrados para a cultivar Monsoy 8001 (Figura 2A), sendo que, para o maior teor de água, apenas a maior pressão foi diferente do controle, porém, para o menor teor de água, a menor pressão também apresentou maior quantidade de danos que a testemunha, entretanto, em menor quantidade que o tratamento com maior teor de água e pressão de impacto.

Resultados diferentes entre cultivares são esperados, devido às suas características físicas diferentes, o que justifica o uso de mais de uma cultivar, para a realização de estudos deste tipo. França Neto et al. (2007), em trabalho com soja, confirmaram a diferença de susceptibilidade a danos mecânicos entre cultivares de soja. Os autores basearam-se nos teores de lignina no tegumento das sementes, o que favorece a produção de sementes de melhor qualidade. Segundo Santos et al. (2007), a lignina, além de proporcionar maior resistência das sementes às injúrias mecânicas, confere maior tolerância à deterioração por umidade e menor velocidade de hidratação das sementes.

Para confirmar estas constatações, quando analisada a cultivar Vencedora, com relação aos danos mecânicos leves (Figura 1B), na avaliação pré-armazenamento, não foram observadas diferenças 


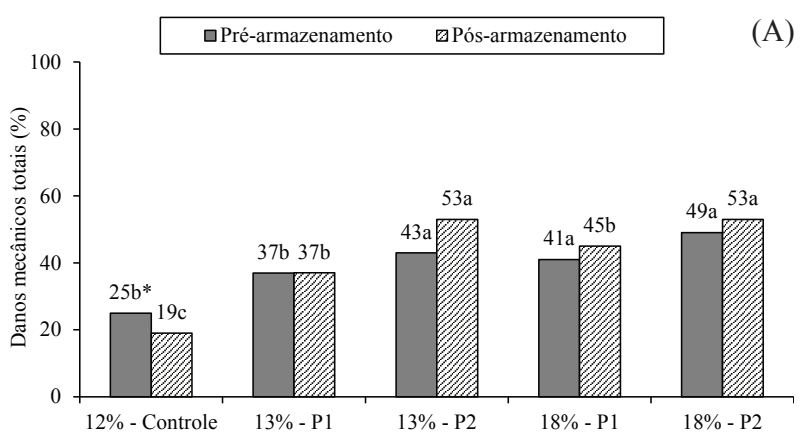

(B)

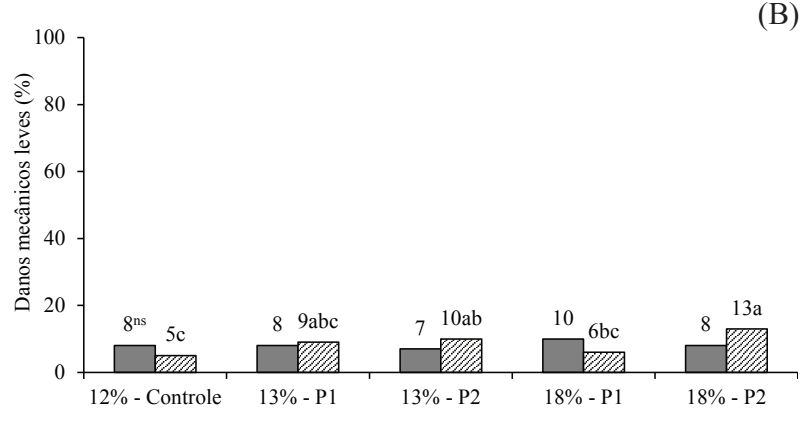

(C)

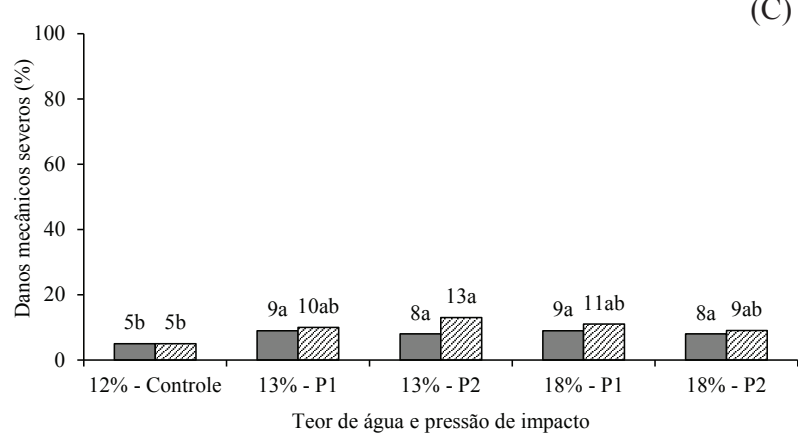

Figura 1. Danos mecânicos (\%) totais (A), leves (B) e severos (C), para a cultivar Vencedora, avaliados por meio do teste de tetrazólio (TZ), em pré e pós-armazenamento, sob duas pressões de impacto $(\mathrm{P} 1=551,6 \mathrm{KPa}$ e $\mathrm{P} 2=$ $965,3 \mathrm{KPa})$, com diferentes teores de água (12\%, 13\% e 18\%) (Piracicaba, SP, 2008). * Médias seguidas por letras iguais, em cada período de armazenamento, não diferem entre si, pelo teste Tukey, a 5\%. ${ }^{\text {ns Não }}$ significativo.

entre os tratamentos. Porém, após o armazenamento, pôde-se constatar tendência de aumento dos danos, com o aumento da pressão de impacto dentro de cada teor de água, sendo que, para as pressões mais altas, constatou-se maiores percentagens de danos mecânicos, em relação à testemunha. Já para a cultivar Monsoy 8001 (Figura 2B), não foram observadas diferenças, o que confirma a resposta diferenciada de cada cultivar aos efeitos da pressão de impacto.
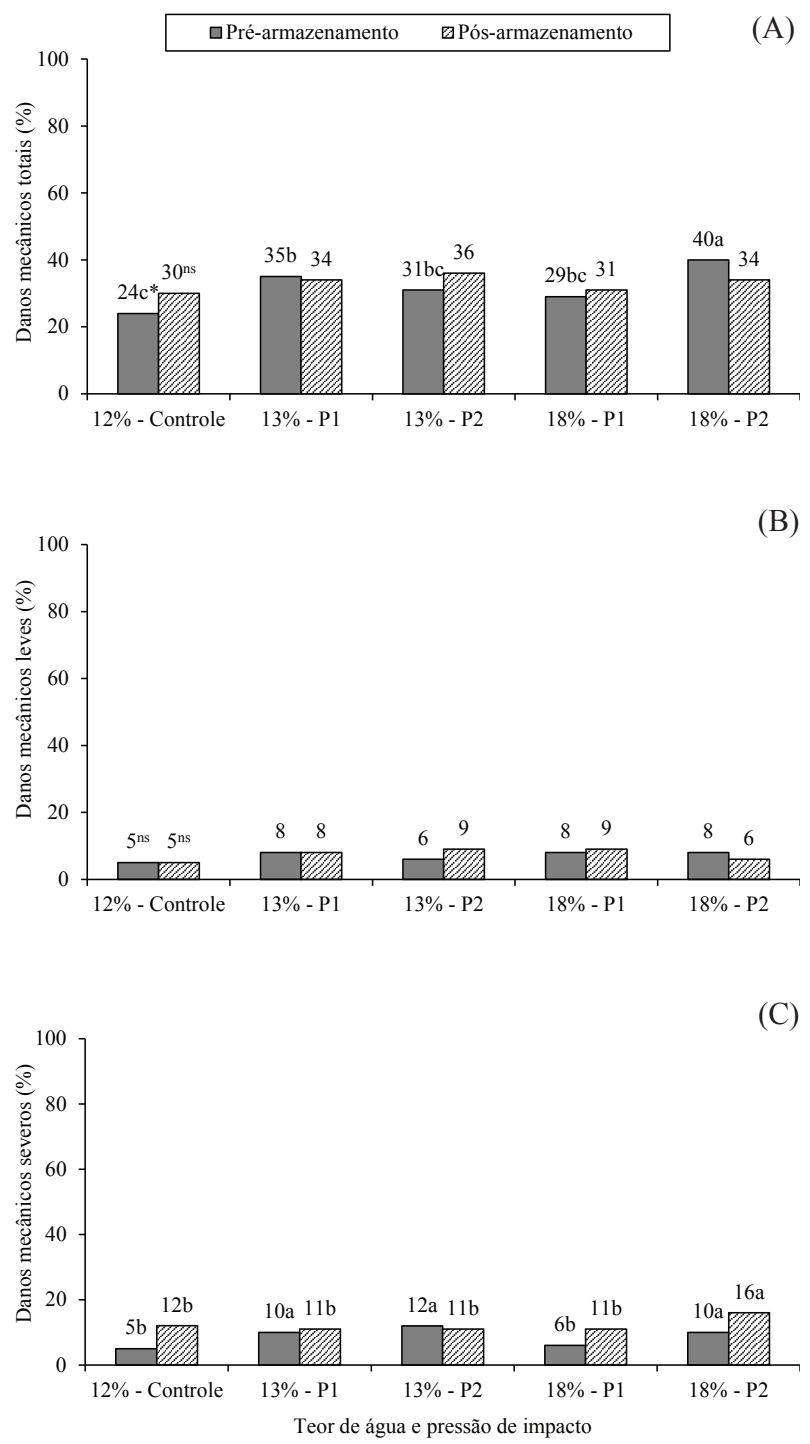

Figura 2. Danos mecânicos (\%) totais (A), leves (B) e severos (C), para a cultivar Monsoy 8001, avaliados por meio do teste de tetrazólio (TZ), em pré e pós-armazenamento, sob duas pressões de impacto $(\mathrm{P} 1=551,6 \mathrm{KPa}$ e $\mathrm{P} 2=$ $965,3 \mathrm{KPa})$, com diferentes teores de água (12\%, 13\% e 18\%) (Piracicaba, SP, 2008). * Médias seguidas por letras iguais, em cada período de armazenamento, não diferem entre si, pelo teste Tukey, a 5\%. ${ }^{\text {ns }}$ Não significativo.

$\mathrm{Na}$ análise de danos mecânicos severos, para a cultivar Vencedora (Figura 1C), observou-se, na análise pré-armazenamento, a ocorrência de danos mecânicos imediatos, sendo que não houve diferenças entre os tratamentos submetidos aos impactos, porém, pôde-se observar, após o armazenamento, que os tratamentos submetidos a maiores pressões de impacto apresentaram as maiores percentagens de danos mecânicos. 
Para a cultivar Monsoy 8001 (Figura 2C), observou-se, no pré-armazenamento, que os danos mecânicos foram superiores ao controle, para ambas as pressões, quando as sementes apresentavam 13\% de teor de água. Quando estas apresentavam teor de água mais elevado (18\%), foi necessária maior pressão de impacto, para a ocorrência mais acentuada de danos mecânicos, o que demonstra uma relação entre o teor de água, a pressão de impacto e a severidade dos danos mecânicos nas sementes. Evans et al. (1990) concluíram que o teor de água e a velocidade de impacto são fatores importantes, que definem a intensidade das injúrias mecânicas em sementes de soja.

Dentre as ferramentas associadas à técnica de análise de imagens, o teste de raios $\mathrm{X}$ permite identificar, de maneira eficaz, danos mecânicos externos e internos em sementes (Cicero \& Banzatto Júnior 2003, Obando-Flor et al. 2004, Mondo et al. 2009) e vem sendo utilizado, inclusive, para outros estudos em tecnologia de sementes, como avaliação da morfologia interna (Mondo \& Cicero 2005, Kobori et al. 2012), danos durante a secagem (Menezes et al. 2012) e danos por umidade (Forti et al. 2010). Pinto et al. (2007, 2009) também comprovaram a eficiência da técnica para avaliar, além dos danos mecânicos, os causados por percevejos e por umidade. Os mesmos autores observaram correlação positiva entre os resultados obtidos no teste de raios $\mathrm{X}$ e no teste de tetrazólio, para os danos severos.

Ao avaliar os resultados deste trabalho pela técnica de análise de imagens (Figura 3), foi possível observar, para a cultivar Vencedora (Figura 3A), isoladamente, que, para as menores pressões, o aumento do teor de água nas sementes resultou em aumento de danos severos nas mesmas, passando de 4 para 6 . O mesmo não ocorreu para a cultivar Monsoy 8001 (Figura 3B), já que, independentemente da pressão de impacto, as sementes mais secas apresentaram maior incidência de danos. Porém, para as sementes
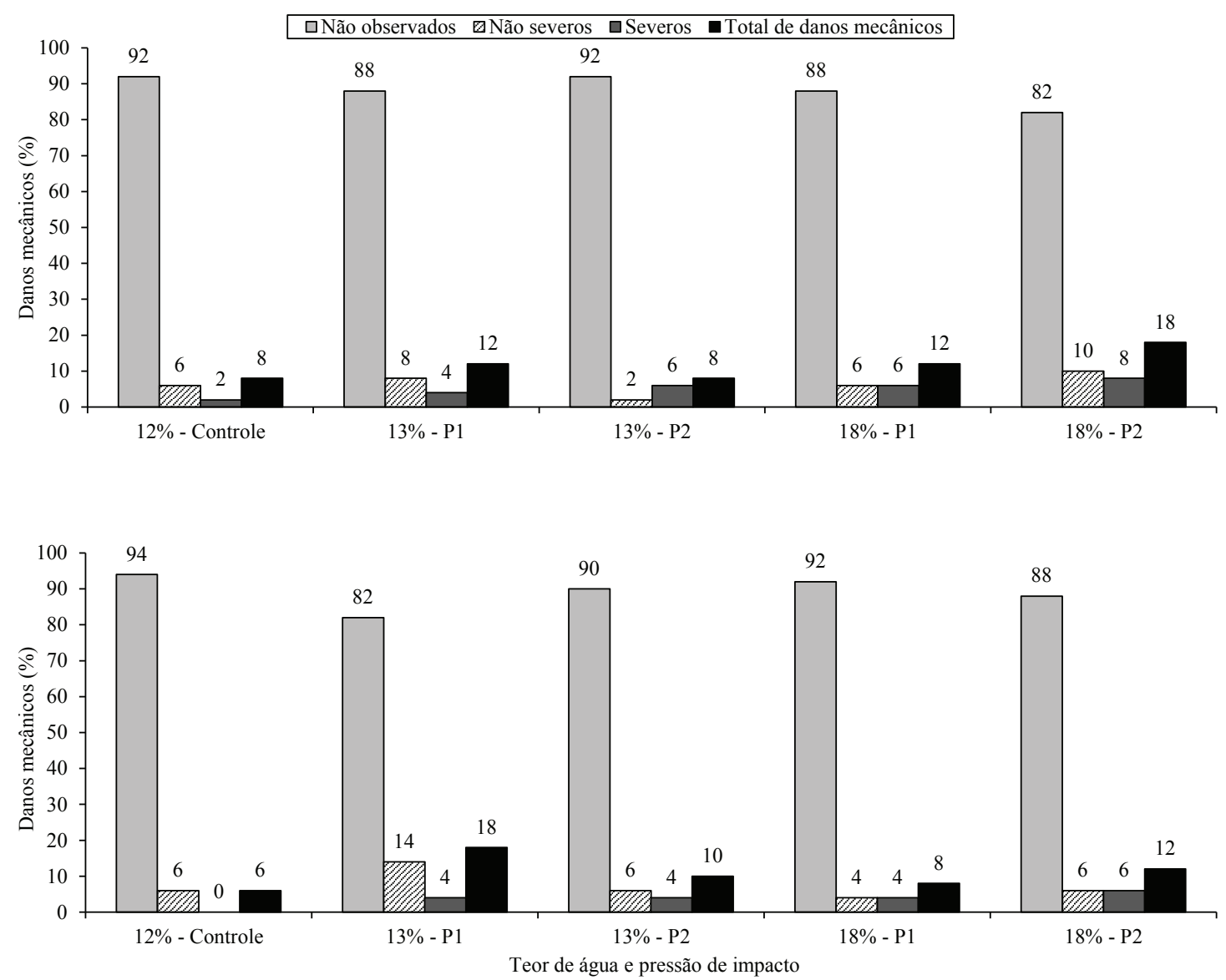

(B)

Figura 3. Danos mecânicos (\%) avaliados pelo teste de raios X, em sementes de soja, para a cultivar Vencedora (A) e Monsoy 8001 (B), com diferentes teores de água $(12 \%, 13 \%$ e $18 \%)$, submetidas a duas pressões de impacto $(\mathrm{P} 1=551,6 \mathrm{KPa}$ e $\mathrm{P} 2=$ 965,3 KPa) (Piracicaba, SP, 2008). 
com maiores teores de água, os danos tenderam a ser mais severos.

As variações observadas durante este experimento estão muito ligadas ao local do impacto. Foi possível observar, com o auxílio das imagens obtidas em raios $\mathrm{X}$ e imagens das plântulas resultantes do teste de germinação, que, apesar da pressão de impacto elevada e das diferenças do teor de água nas sementes, o local de impacto em sementes de soja é de grande importância, principalmente quando os danos ocorrem diretamente no eixo embrionário.

Nas Figuras 4A e 4C, pode-se observar o dano ocasionado em pontos diferentes da semente, sendo que, na Figura 4A, o impacto não incidiu diretamente no eixo, e, apesar de resultar em uma plântula anormal, a severidade foi atenuada (Figura 4B), enquanto, na semente da Figura 4C, o dano atingiu diretamente o eixo embrionário, resultando em uma plântula anormal (Figura 4D).

Carvalho et al. (2011), estudando danos mecânicos em sementes de milho, também constataram o efeito da localização dos danos na qualidade das sementes, assim como Mondo et al. (2009), em trabalho com sementes de feijão. Este tipo de análise só é possível pela utilização da técnica de análise de ima-

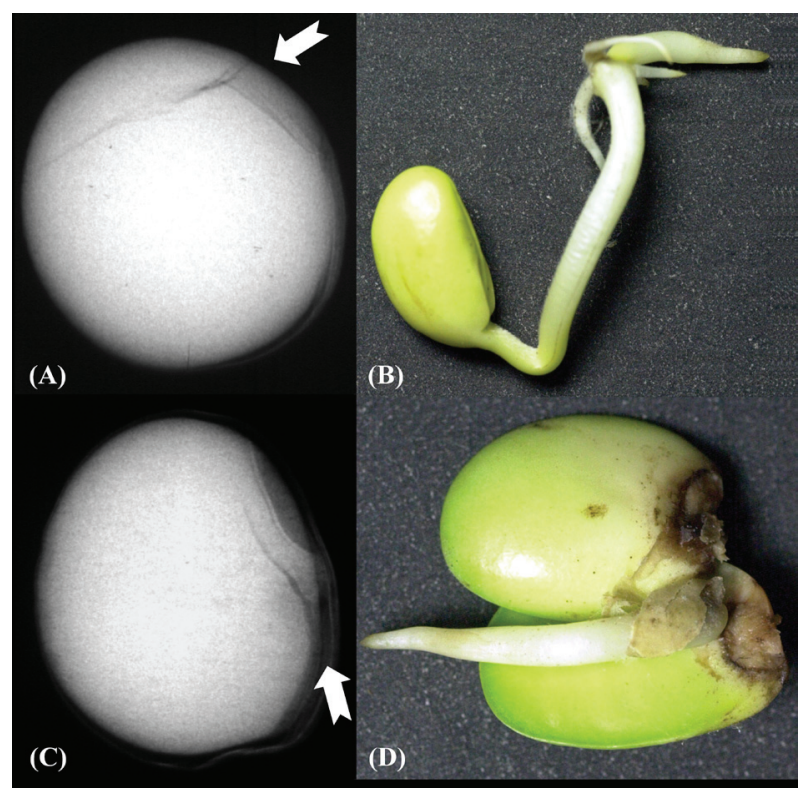

Figura 4. Semente de soja da cultivar Vencedora, com 13\% de teor de água, submetida à pressão de $965,3 \mathrm{KPa}$, imagem de raios X (A) e plântula anormal resultante (B); e semente de soja da cultivar Monsoy 8001 , com $18 \%$ de teor de água, submetida à pressão de 965,3 KPa, imagem de raios X (C) e plântula anormal resultante (D) (Piracicaba, SP, 2008). gem, que possibilita o estabelecimento de relações causa-efeito e permite entender os resultados obtidos.

A semente de soja é muito sensível a danos mecânicos, visto que o eixo embrionário está situado sob um tegumento pouco espesso, que, praticamente, não the confere proteção (França Neto \& Henning 1984). Segundo Andrade et al. (1998), a região do hilo das sementes é a mais sensível ao impacto. Sabe-se que as sementes de soja, assim como as de feijão, por apresentarem o eixo embrionário relativamente exposto e o tegumento pouco espesso, são bastante susceptíveis a danos mecânicos. Assim, é esperada a influência do local de impacto, independentemente da pressão com a qual foi ocasionado o dano (Andrade et al. 1998, Mondo et al. 2009).

\section{CONCLUSÕES}

1. A pressão de impacto e o teor de água nas sementes exerceram efeitos diretos na severidade do dano mecânico, em sementes de soja, porém, o local do impacto exerceu maior influência do que aqueles fatores.

2. A técnica de análise de imagens foi de grande utilidade na avaliação de danos mecânicos em sementes de soja, possibilitando a observação detalhada do efeito de diferentes fatores.

\section{REFERÊNCIAS}

ANDRADE, E. T. et al. Efeitos de danos mecânicos controlados sobre a qualidade fisiológica de sementes de feijão durante o armazenamento. Revista Brasileira de Armazenamento, Viçosa, v. 23, n. 2, p. 41-51, 1998.

ANDRADE, E. T. et al. Efeito do impacto mecânico controlado sobre a qualidade fisiológica de sementes de feijão. Engenharia na Agricultura, Viçosa, v. 7, n. 3, p. 148-159, 1999.

BRASIL. Ministério da Agricultura, Pecuária e Abastecimento. Secretaria de Defesa Agropecuária. Regras para análise de sementes. Brasília, DF: MAPA/ ACS, 2009.

CARVALHO, D. C. de et al. Avaliação da resistência mecânica de grãos de milho via teste de impacto. Revista Brasileira de Engenharia Agrícola e Ambiental, Campina Grande, v. 15, n. 7, p. 724-730, 2011.

CARVALHO, N. M.; NAKAGAWA, J. Sementes: ciência, tecnologia e produção. 4. ed. Jaboticabal: Funep, 2000.

CARVALHO, T. C.; NOVEMBRE, A. D. L. C. Qualidade de sementes de soja colhidas de forma manual e mecânica 
com diferentes teores de água. Semina Ciências Agrárias, Londrina, v. 33, n. 1, p. 155-166, 2012.

CICERO, S. M.; BANZATTO JÚNIOR, H. L. Avaliação do relacionamento entre danos mecânicos e vigor, em sementes de milho, por meio da análise de imagens. Revista Brasileira de Sementes, Viçosa, v. 25, n. 1, p. 2936, 2003.

CICERO, S. M. et al. Evaluation of mechanical damages in seeds of maize (Zea mays L.) by X-ray and digital imaging. Seed Science and Technology, Bassersdorf, v. 26, n. 3, p. 603-612, 1998.

COSTA, N. P. et al. Avaliação da qualidade de sementes e grãos de soja provenientes da colheita mecanizada, em diferentes regiões do Brasil. Engenharia Agrícola, Jaboticabal, v. 22, n. 2, p. 211-19, 2002.

EMPRESA BRASILEIRA DE PESQUISA AGROPECUARIA (Embrapa). Tecnologias de produção de soja - Paraná - 2005. Londrina: Embrapa Soja, 2005. (Sistemas de produção, 5).

EVANS, M. D.; HOLMES, R. G.; McDONALD, M. B. Impact damage to soybean seed as affected by surface hardness and seed orientation. Transactions of the ASEA, St. Joseph, v. 33, n. 1, p. 234-240, 1990.

FORTI, V. A.; CICERO, S. M.; PINTO, T. L. F. Avaliação da evolução de danos por 'umidade' e redução do vigor em sementes de soja, cultivar TMG113-RR, durante o armazenamento, utilizando imagens de raios $\mathrm{X}$ e testes de potencial fisiológico. Revista Brasileira de Sementes, Viçosa, v. 32, n. 3, p. 123-133, 2010.

FRANÇANETO, J. B. Teste de tetrazólio para determinação do vigor de sementes. In: KRZYZANOWSKI, F. C.; VIEIRA, R. D.; FRANÇA NETO, J. B. (Eds.). Vigor de sementes: conceitos e testes. Londrina: Abrates, 1999. p. 1-7.

FRANÇA NETO, J. B.; HENNING, A. A. Qualidade fisiológica e sanitária de sementes de soja. Londrina: Embrapa-CNPSo, 1984. (Circular técnica, 9).

FRANÇA NETO, J. B. et al. Tecnologia da produção de sementes de soja de alta qualidade. Londrina: EmbrapaCNPSo, 2007. (Circular técnica, 40).
HENNING, A. A.; FRANÇA NETO, J. B. Secagem e armazenamento de sementes de soja. In: ARANTES, N. E.; SOUZA, P. I. M. (Eds.). Cultura da soja nos Cerrados. Piracicaba: Potafos, 1993. p. 437-463.

KOBORI, N. N.; CICERO, S. M.; MEDINA, P. F. Teste de raios $X$ na avaliação da qualidade de sementes de mamona. Revista Brasileira de Sementes, Viçosa, v. 34, n. 1, p. 125-133, 2012.

MENEZES, N. L. et al. Using X-rays to evaluate fissures in rice seeds dried artificially. Revista Brasileira de Sementes, Viçosa, v. 34, n. 1, p. 70-77, 2012.

MONDO, V. H. V.; CICERO, S. M. Análise de imagens na avaliação da qualidade de sementes de milho localizadas em diferentes posições na espiga. Revista Brasileira de Sementes, Viçosa, v. 27, n. 1, p. 9-18, 2005.

MONDO, V. H. V. et al. Avaliação de danos mecânicos em sementes de feijão por meio da análise de imagens. Revista Brasileira de Sementes, Viçosa, v. 31, n. 2, p. 27-35, 2009.

OBANDO-FLOR, E. P. et al. Avaliação de danos mecânicos em sementes de soja por meio da análise de imagens. Revista Brasileira de Sementes, Viçosa, v. 26, n. 1, p. 68-76, 2004.

PINTO, T. L. F.; CICERO, S. M.; FORTI, V. A. Avaliação de danos por umidade, em sementes de soja, utilizando a técnica de análise de imagens. Revista Brasileira de Sementes, Viçosa, v. 29, n. 3, p. 31-38, 2007.

PINTO, T. L. F. et al. An assessment of mechanical and stink bug damage in soybean seed using X-ray analysis test. Seed Science and Technology, Bassersdorf, v. 37, n. 1, p. 110-120, 2009.

ROSSETTO, C. A. V.; FERNANDEZ, E. M.; MARCOS FILHO, J. Metodologias de ajuste do grau de umidade e comportamento das sementes de soja no teste de germinação. Revista Brasileira de Sementes, Viçosa, v. 17, n. 2, p. 171-178, 1995.

SANTOS, E. L. et al. Qualidade fisiológica e composição química das sementes de soja com variação na cor do tegumento. Revista Brasileira de Sementes, Viçosa, v. 29, n. 1, p. 20-26, 2007. 